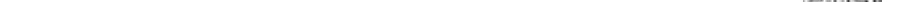





\section{Os modos de vida e a transformação recente da agricultura na Reserva Indígena Lalima, município de Miranda MS* $^{*}$}

Claudinei de Souza**

\section{Introdução}

A agricultura é uma prática tradicional entre nós, Terena, adquirida de nossos antepassados e ainda bastante valorizada na Reserva Indígena Lalima, sendo que dessa atividade as famílias retiram seu sustento. Observamos problemas importantes que levaram à transformação da forma de produção tradicional para uma nova organização na qual a rotação de culturas ${ }^{1}$ e o pousio do solo $^{2}$, enquanto técnicas que garantiam produtividade e equilíbrio ambiental, já não se constituem mais presentes devida à pouca disponibilidade de terras disponíveis para agricultura.

Procuro aqui apresentar a maneira como a agricultura está sendo desenvolvida em Lalima. Portanto, da ênfase à pesquisa de campo, em que se realizou o levantamento dos dados por meio do diálogo com a população local, ou seja, pela observação empírica (observação real do problema). Com isso, procura entender como ocorre a prática da agricultura, as dificuldades enfrentadas pelos agricultores bem como as potencialidades e possibilidades de melhorar suas condições de vida vinculadas à essa atividade.

\section{Forma de produção num processo histórico}

Para definir o que é agricultura, recorro a George (1991, p. 9), que diz: " pode-se definir a agricultura como uma domesticação das plantas e dos animais úteis ao homem". Entretanto, para os Terena de Lalima "é uma fonte de alimentos e significa que por meio dela cultivam sua sobrevivência física e cultural". Assim, a forma com que a população de Lalima pratica a

* Esta pesquisa foi orientada pelo professor Roni Mayer Lomba, do curso de Geografia da Universidade Estadual de Mato Grosso do Sul.

** Concluiu o curso de Geografia na Universidade Estadual de Mato Grosso do Sul (UEMS), em Glória de Dourados, onde morou por quatro anos. Atualmente mora em Lalima, onde ministra aulas de Geografia no Ensino Fundamental e no Ensino Médio. sousaclaudinei@yahoo.com.br 
agricultura hoje tem resquício dos nossos antepassados, pois o conhecimento implantado, desde a escolha da área para o plantio até o momento da colheita, foi concebido através de experiências com os mais velhos. Portanto, uma das características culturais dos Terena é o papel desempenhado pela agricultura na sua economia.

Ainda hoje a agricultura é a vocação mais valorizada entre nós, como se percebe na Reserva Indígena Lalima. De acordo com Azanha (2004):

A vocação de agricultores do povo Terena ainda está presente nas áreas indígenas, em que todas as famílias possuem pelo menos uma pequena área de lavoura, porém, sem conseguir obter dela a renda necessária para manter, durante todo o ano, o seu grupo familiar em outras necessidades básicas.

O cultivo mecanizado da terra ${ }^{3}$ iniciou a partir de 1980 e permanece até os dias de hoje. A partir dessa data houve aumento na produção e intensificou a comercialização dos produtos cultivados em Lalima. Isso ocorreu com a inserção de máquinas e a facilidade do transporte dos produtos para a cidade. Segundo Atanásio Alves ${ }^{4}$ :

Em 1980, Lalima recebeu pela FUNAI um trator VALMET 65 e uma caminhonete Picap. Já em 1982, a liderança local conseguiu com a Receita Federal de Campo Grande, um caminhão F.4000, que favoreceu o transporte de cereais para Miranda. Logo, foi comprado com recurso da venda de bovinos da própria comunidade, um trator Massey Fergusson 290 com arado, grade e niveladora, que desenvolveu muito bem a agricultura aumentando o plantio e a colheita.

Na forma de trabalhar com a terra mecanizada, a possibilidade de ampliar a área é maior. Além disso, planta-se com máquinas e as sementes são selecionadas e utilizadas em grande parte, ano após ano. Uma pequena parcela espera o repasse de sementes pela Funai, porém há casos em que são compradas ou emprestadas de outros agricultores, ou seja, utiliza a forma de parceria e compra.

Os agricultores trabalham em conjunto, em que predomina o grupo familiar entre pai e filhos. Os meninos, a partir dos sete anos de idade, já acompanham seus pais na roça e, no período da limpa e colheita, algumas mulheres também se encarregam dessa atividade, porém, há casos em que a forma de trabalho ocorre individualmente. Isso é comum quando os filhos ainda são pequenos. Contudo, quem cuida mais da roça é o chefe da família e para se manter uma boa lavoura necessita de oito horas de trabalho diário. Parte da produção agrícola também se destina ao mercado, mas não há utilização de trabalho assalariado.

Hoje em Lalima quem trabalha com frequência na agricultura são os adultos e velhos, já entre os jovens, minoria realiza tal atividade fre- 
quentemente (só em momentos de limpa e colheita). Portanto, estes últimos, buscam o trabalho externo em troca de salário, por verem poucas perspectivas financeiras nesse ramo, o que representa para nós, Terena, a perda de parte da cultura, visto que os conhecimentos dos antepassados com isso se perdem. Além do mais, abala a estrutura familiar pois os jovens se ausentam de suas residências comprometendo o elo familiar que sempre existiu em nossa grande povoação.

Além do mais, encontram-se dificuldades com a produção que é direcionada ao comércio, pois quase não se compra mais produtos in natura como é o caso do feijão e, quando isso ocorre é por preço abaixo do mercado. O feijão hoje está sendo vendido na cidade por $\mathrm{R} \$ 150,00 \mathrm{o}$ saco de 60 quilos ou, o que é mais comum, para intermediários que buscam na reserva pagando $\mathrm{R} \$ 120,00$ o mesmo saco de 60 quilos.

A remuneração dos agricultores depende da quantidade de sacas que vende, ou seja, varia de família para família. De acordo com Souza, (2005, p. 131): “Em boa parte das sociedades indígenas existentes no Brasil, a 'ida ao mercado', representada por compras e trocas efetuadas com comerciantes de localidades próximas significa a imposição de alguns tipos de desvantagem econômica aos índios".

No caso da mandioca, é comercializada em feiras e restaurantes da cidade de Miranda onde são vendidos por R\$20,00 os sacos de aproximadamente 50 quilos ou entregue a uma fecularia que busca na reserva por $\mathrm{R} \$ 7,00$ a caixa. Segundo os produtores, traz prejuízo porque as raízes pequenas ficam como sobra e perde-se tudo.

Além dos produtos acima citados, também se planta em maior quantidade arroz ${ }^{5}$, milho, feijão de corda, abóbora, melancia, batata, maxixe, banana entre outros. Parte do que é produzido também é comercializado, em pequena quantidade, no comércio da cidade de Miranda.

No caso da venda em maior quantidade como o milho, o feijão e a mandioca, reúnem-se os agricultores indígenas e procuram direcionar seus produtos no mercado, geralmente por meio de intermediários. Quanto aos destinados às feiras e restaurantes em menor quantidade, a venda ocorre individualmente. A comercialização dos Terena de Lalima não é individual, mas necessita que sua organização seja aprimorada.

$\mathrm{O}$ ano agrícola na reserva inicia-se em agosto, tendo seu término em março/abril, com o plantio de feijão da "seca". Assim, a produção agrícola obtida em Lalima é destinada ao consumo familiar e, quando possível, para venda, o que é mais raro devido ao baixo preço e às exigências do comprador e do consumidor. Segundo Oliveira, (1990, p. 68): 
no trabalho camponês, uma parte da produção agrícola entra no consumo direto do produtor, do camponês, como meio de subsistência imediata, e a outra parte, o excedente, sob a forma de mercadoria, é comercializada.

Além de se estruturarem na produção através da força familiar, existe também mutirão quando há necessidade de "acelerar" o trabalho, a exemplo da limpa e colheita. Essas formas de organização no trabalho se assemelham com alguns dos elementos estruturais da produção camponesa apresentada por Tavares dos Santos (apud Oliveira, 1990, p. 6970), através de seu livro "Colonos do Vinho", como: "a força de trabalho familiar; a ajuda mútua entre os camponeses através do mutirão ou a troca pura e simples de dias de trabalho entre eles; a jornada de trabalho, quando não há rigidez de horário de trabalho quando há momento de muito trabalho". Tanto no trabalho familiar quanto no mutirão não há pagamento monetário, podendo ocorrer no mutirão trocas de dias de trabalho ou pagamento em produtos.

Cada família cultiva entre $1 \frac{1}{2} 2$ e 2 hectares, seja em área mecanizada ou de roçado. Muitos optam pelo cultivo em coivaras $^{6}$ devido ao atraso dos mínimos recursos enviados pela Funai (óleo diesel e sementes) ou pelo fato essas áreas serem mais ricas em nutrientes permitindo maiores colheitas e melhores qualidades dos produtos.

Além de tudo, se percebe que é uma forma não-capitalista de produção, pois se trata de uma produção apenas para subsistência, ou seja, a forma de produção obedece a uma forma contraditória do capital. Com isso, as famílias não possuem conhecimento do valor monetário de suas colheitas seja por mês, ano, ou melhor, não contabilizam o total da produção. Embora não quantifiquem os valores produzidos, reconhecem que a produção é insuficiente e são obrigados a desenvolverem outras atividades como estratégias de sobrevivência.

Como foi mencionado anteriormente, a vocação pela agricultura em Lalima foi sempre passada de pai para filho. Isso foi bastante lembrado pelos mais velhos e cabe aqui mencionar o relato de Martins Gomes que disse": "Antigamente, não faltavam alimentos, fazia um roçado e tinha planta o ano inteiro, tinha bastante terra, podia derrubar e plantar onde quisessem.

Isso quer dizer que cultivavam, em uma mesma área, variedades de plantas e praticavam a rotação de culturas e o pousio do solo. Hoje, com o aumento da população, a inserção de tratores e adoção de concepções capitalistas trouxe para os Terena diversas novas demandas da sociedade capitalista de consumo. Diante disso, a agricultura passou a 
ser vista pela população como uma possibilidade de renda através da comercialização dos produtos, para supri-los em outras necessidades básicas.

\section{As principais demandas apontadas pela população}

Atualmente surgem concepções para melhorar e ampliar o sistema produtivo, a fim de obter algum retorno financeiro sem deixar de lado o conhecimento tradicional. Um dos elementos fundamentais que poderia possibilitar melhores condições de vida aos agricultores é a ampliação da área da reserva.

Além do aumento da área, outro aspecto destacado pelos entrevistados é um acompanhamento de técnicos agrícolas ou agrônomos para auxiliá-los, pois necessitam de outros conhecimentos. Em relação a isso, foi lembrado por Ermelindo de Souza que " ${ }^{~ " N e s s e ~ a n o, ~ e n t r e ~ f e v e r e i r o ~ e ~}$ junho de 2008, surgiu uma doença nas plantações de mandioca que levou à perda de parte do plantio".

Além das doenças e/ou pragas que sempre aparecem nas lavouras, também se percebe a necessidade de construir curvas de nível em alguns locais para evitar os efeitos da erosão e perda da produtividade dos solos.

Outra demanda encontrada em Lalima é o descaso com que o "poder público" tem com o povo local. Esses órgãos, muita vezes trabalham sob forma de assistencialismo ou clientelismo, ou melhor, através de domínio político. A esse respeito temos preciosos depoimentos de alguns professores da reserva. Segundo Deli de Souza Alves " "A presença do poder público na reserva é atendendo com algumas mínimas ações, algumas vezes interferindo no modo de vida e organização interna".

Além disso, Valdelei de Oliveira afirma que ${ }^{10}$ "Quando há incentivo e/ou participação do 'poder público' é por meio de período eleitoreiro".

Para Eduardo dos Santos Rodrigues ${ }^{11}$ "A presença do 'poder público' nas ações desenvolvidas na reserva é de uma maneira de domínio politico".

Contudo, os agricultores necessitam de investimento e incentivo por parte do "poder público", fornecendo máquinas, sementes e técnicos agrícolas ou agrônomos para acompanhá-los, não no sentido do assistencialismo ou clientelismo como acontece atualmente. De um lado são feitas doações de alimentos (cestas básicas), com o discurso de que com isso pode-se trabalhar na lavoura, mas, por outro lado, não fornecem os insumos necessários como máquinas, óleo diesel e sementes no tempo 
certo de preparo do solo e plantio. Geralmente, os moradores são beneficiados com o mínimo que possam trabalhar e já no período ultrapassado, levando à perda total ou parcial da plantação, por motivo da seca ou excesso de chuvas. De acordo com Ermelindo de Souza:

O que nós precisamos é de apoio do governo para trabalhar com área maior a fim de ampliar a produção e o lucro pra melhorar nossas condições de vida enquanto agricultor. Também precisamos de um transporte próprio para levar os produtos para vender e um lugar certo para entregar as coisas. Nós plantamos só isso porque é o que agüentamos fazer, não é por falta de coragem e vontade de trabalhar.

Quando ele se refere ao apoio do governo é no sentido de poder contar com máquinas, óleo diesel, sementes, acompanhamento de técnicos no período certo e de não faltar coragem e vontade de trabalhar. É melhorar a situação econômica sem desvincular da agricultura herdada dos antepassados. Diante disso, fica clara a vontade dos agricultores de trabalhar por conta própria, ou seja, ter máquinas à disposição para quando for necessário, dentro de uma ótica capitalista de produção. Ainda ressaltam que, de início, precisam do apoio do "poder público" para depois poder "andar com as próprias pernas". Conforme Deli de Souza Alves:

Seria importante implantar os mesmos programas que assistem os assentados nas áreas indígenas para poderem até comprar máquinas". Com isso, lembra-se do Programa Nacional de Fortalecimento da Agricultura Familiar (PRONAF). Para tentar se inserir nesse programa, é necessário que se crie uma organização entre os agricultores dentro da reserva.

Vale ressaltar que todos os entrevistados reconhecem a falta de organização entre os agricultores e também lamentam a ausência da FUNAI, para articular os demais setores ou esferas governamentais com a população de Lalima, no intuito de melhorar as condições de vida da população.

Mediante reivindicações dirigidas, a Funai tem como justificativa a falta de recurso, que pouco contribui para atender os anseios dos trabalhadores (agricultores).

Do ponto de vista histórico, deve-se observar que as relações estabelecidas ao longo dos anos entre as populações indígenas e o Estado, em especial de órgãos indigenistas oficiais, o Serviço de Proteção aos Índios (SPI) e a Funai, foram basicamente relações clientelistas e assistencialistas que promoveram a cristalização de um campo desigual de poderes e comprometeram a concepção de autonomia e autodeterminação dos povos indígenas. Há, portanto, grande receio dos indígenas e indigenistas em relação ao formato que os programas terão, pois podem vir a reforçar essas relações viciadas e manter 
desequilibradas as forças no plano local em que tais comunidades se encontram. (Fialho, 2005, p. 72)

Outro fator que dificulta a inserção da comunidade em Programas ou Projetos é a forma como eles são elaborados, visto que não levam em consideração as diferenças entre as sociedades, a exemplo de um bairro da cidade, um assentamento ou uma população indígena. Em se tratando dos povos indígenas, também não levam em consideração as especificidades existentes.

Lembrando da questão burocrática que existe por parte dos programas (a exemplo do Pronaf) que dificulta a inserção na Reserva Indígena Lalima ou a absorção pela população, Souza $(2005$, p. 126127) esclarece que:

Existem ainda uma série de exigências para a operacionalização do programa que inviabilizam a tomada por empréstimos por índios. Os indivíduos devem morar em municípios que possuam Conselho municipal de Desenvolvimento rural sustentável, que deve identificar os possíveis beneficiários e encaminhar ao agente financeiro uma relação de nomes e números de carteiras de identidade e CPFs para análise do cadastro. Quem tiver seu cadastro aprovado, deve providenciar uma declaração de aptidão (fornecida pela Funai) e proposta de crédito para seleção e homologação pelo conselho Estadual de Desenvolvimento rural sustentável, que, ao homologar as propostas, reencaminham-as ao agente financeiro para aprovação e liberação dos recursos. São tantos os documentos exigidos (declaração de aptidão, CPF, carteira de identidade, titulo de eleitor, documentos da terra e proposta de crédito), que até mesmo uma comunidade organizada em associação dificilmente consegue obtê-los.

Lembro que a forma de produção para subsistência que foi desenvolvida ao longo dos anos pela população de Lalima não corresponde à necessidade do momento. Apesar das divergências entre concepções (conservadoras e capitalistas), na maneira de organização e técnicas de produção, predominam a concepção de novos conhecimentos, novas técnicas de manejo do solo e cultivo dos produtos voltados também para o mercado. Portanto, necessita de uma política de inserção de uma agricultura voltada também para o mercado, não necessariamente produzir em larga escala ou monocultura, mas uma pequena produção familiar indígena ou coletiva que gere renda.

Desse modo, não só valoriza a cultura deixada pelos antepassados, mas faz com que a agricultura seja uma atividade em que os agricultores indígenas possam produzir seu próprio alimento e vender o excedente, ou seja, em que possam melhorar suas condições de vida sem desvincular desta atividade que sabem muito bem desenvolver. 
Para que isso seja concretizado, necessita da ampliação da área da reserva, pois ainda é possível cultivar na terra de toco ${ }^{12}$, fazer rotação de cultura e pousio do solo porque nem todos trabalham com áreas significativas que trazem uma produção razoável ou um retorno financeiro, ou seja, cultivam entre $1 / 2$ e 1 hectare. Essa pequena área cultivada resulta das condições e recursos disponíveis, o que faz com que os moradores de Lalima trabalhem a maior parte do ano nas usinas de açúcar e álcool.

Entretanto, estimulando uma forma de agricultura capitalista em todas as famílias, a área será insuficiente para que possam produzir o necessário que venha suprir as necessidades básicas, como comprar roupas, calçados, eletrodomésticos entre outros. Isso é explícito porque, dividindo a área de 3.021 hectares por 320 famílias, fica aproximadamente 9,44 hectares para cada família. No entanto, parte da área da reserva não é cultivável, pois é de preservação ambiental, como as submontanas e a margem do rio Miranda, além daquelas destinadas à criação de gado, de aproximadamente 450 hectares.

Além do mais, verifica-se uma necessidade maior de organização interna através de associações ou cooperativas para trabalhar na elaboração de projetos e absorção de recursos. Além de se fortalecer através de uma política de agregação de valores dos produtos articulando diretamente o mercado. Sem contar que os conhecimentos técnicos/científicos podem fortalecer a demanda desde a ampliação de áreas de cultivo bem como o aumento da produção e consequentemente a renda.

\section{Considerações Finais}

Este estudo permitiu ouvir e registrar as dificuldades enfrentadas pelos agricultores terena. Como resultado foi possível desvendar a importância da agricultura já que a maioria dos indígenas tem esta atividade como principal fonte de alimentos.

$\mathrm{O}$ aporte metodológico garantiu a possibilidade para conhecer a realidade através de observações a partir da realidade, considerando que a reserva tem na agricultura sua principal atividade de produção de alimentos para subsistência e possibilidade de adquirir renda por meio da comercialização dos produtos.

A respeito de grupos de trabalhos, associações ou cooperativas na agricultura, não existe nada disso em Lalima e é um problema identificado pelos indígenas. Portanto, os líderes locais devem procurar fazer reuniões, unir os agricultores no intuito de criar uma organização para que 
criem projetos de melhorias no manejo do solo, de novas técnicas no sentido de melhorar e ampliar a produção.

A agricultura, por ser um costume dos antepassados Terena, a preocupação não é apenas mantê-la viva, mas fazer dela meio de fonte de renda, em que possa fixar a família no processo de produção voltado também para o mercado. Isso porque, cada vez mais aumenta o número de jovens e membros de famílias se deslocando para as fazendas e usinas sucroalcooleiras em Mato Grosso do Sul, na busca de emprego, trabalhando nas condições de semiescravidão. Outras famílias migram para as cidades à procura do mercado de trabalho, na esperança de melhores condições de vida.

As famílias que insistem em continuar trabalhando na agricultura não conseguem tirar dela o suficiente para sobreviver, pois produzem em pequena quantidade. Essa produção em pequena escala não ocorre por opção dos agricultores, mas, pelo fato da dificuldade enfrentada, decorrente do não incentivo do "poder público" no sentido de incentiválos ou atendê-los na ampliação de áreas, de melhorias no plantio e consequentemente no aumento da produção e da renda.

Portanto, o desejo dos agricultores é poder continuar trabalhando nessa atividade e obter renda para suprir outras necessidades básicas, visto que há possibilidade através da organização entre ambos através de uma política de agregação de valores dos produtos, direcionando-os diretamente às cerealistas e fecularias, eliminando os atravessadores.

Evidente que para isso é necessária a ação de políticas e de programas governamentais, além da presença indispensável de conhecimentos técnicos/científicos priorizando a necessidade da produção e a busca de seu desenvolvimento.

\section{Notas}

${ }^{1}$ Consistem em alternar espécies vegetais no decorrer do tempo, numa área agrícola, ou seja, se faz o rodízio de plantas.

${ }^{2}$ Após uma boa produção por alguns anos, o solo fica "fraco" e o agricultor abandona essa área em descanso para que se recupere a partir das próprias plantas, consideradas invasoras ou daninhas e depois de algum tempo, seja restabelecida a fertilidade. Com isso, volta a plantar na área e obter uma boa produção novamente.

${ }^{3} \mathrm{O}$ preparo do solo para o plantio é por meio do uso de trator e arado.

${ }^{4} 66$ anos, Professor aposentado, liderança e morador na Reserva Indígena Lalima. Entrevista concedida em 22/7/08.

${ }^{5} \mathrm{O}$ arroz não é vendido, se planta exclusivamente para o consumo da família. 
${ }^{6}$ Onde se junta a ramagem não atingida pela queima de roça para limpar o terreno para plantar.

${ }^{7} 74$ anos, morador na Reserva Indígena Lalima. Entrevista realizada em 22/7/08.

${ }^{8}$ Agricultor e morador na Reserva Indígena Lalima, entrevista realizada em 23/7/08.

${ }^{9}$ Professor e morador na Reserva Indígena Lalima, entrevista concedida em 23/7/08.

${ }^{10}$ Professor e morador na Reserva Indígena Lalima, entrevista realizada em 22/7/08.

${ }^{11}$ Professor e morador na Reserva Indígena Lalima, entrevista realizada em 22/7/08.

${ }^{12}$ Como os índios de Lalima denominam o cultivo em áreas que são derrubadas com machado, foice e utiliza o fogo para limpar o terreno.

\title{
Referências
}

AZANHA, G. As terras indígenas Terena no Mato Grosso do Sul. São Paulo. CTI, 2004.

FIALHO, Vânia. Avanços e desafios dos mecanismos públicos para segurança alimentar e auto sustentação indígena. In: VERDUM, Ricardo (org.). Assistência técnica e financeira para o desenvolvimento indígena: possibilidades e desafios para políticas públicas. Rio de Janeiro: Contra Capa Livraria/Brasília:Núcleo de Estudos Agrários e Desenvolvimento Rural-MDA, 2005. p. 61-78.

OLIVEIRA, Ariovaldo Umbelino de. Modo capitalista de produção e agricultura. São Paulo: Ática, 1990.

GEORGE, Pierre. Geografia agrícola do mundo. 6. ed. Rio de Janeiro: Bertrand Brasil, 1991.

SOUZA, Marcos Alves de. O PRONAF e os povos indígenas. In: VERDUM, Ricardo (org.). Assistência técnica e financeira para o desenvolvimento indígena: possibilidades e desafios para políticas públicas. Rio de Janeiro: Contra Capa Livraria; Brasília: Núcleo de Estudos Agrários e Desenvolvimento Rural-MDA, 2005. p. 117-138.

\section{Lista dos entrevistados}

\author{
Atanásio Alves \\ Deli de Souza Alves \\ Eduardo dos Santos Rodrigues \\ Ermelindo de Souza \\ Martins Gomes \\ Valdelei de Oliveira
}

\section{Recebido em 22 de outubro de 2009.}

Aprovado para publicação em 3 de fevereiro de 2009. 